\title{
Networked Policymaking Avenues: Assessing the Role of Academics in Digital Policy
}

\section{Citation}

Ashar, Amar, Robert Faris, Urs Gasser. 2016. Networked Policy Making Avenues: Assessing the Role of Academics in Digital Policy (September 23, 2016). Networked Policy Series, Berkman Klein Center Research Publication No. 2016-14.

\section{Published Version}

https://cyber.harvard.edu/publications/2016/NetworkedPolicymaking

\section{Permanent link}

http://nrs.harvard.edu/urn-3:HUL.InstRepos:28552572

\section{Terms of Use}

This article was downloaded from Harvard University's DASH repository, and is made available under the terms and conditions applicable to Other Posted Material, as set forth at http:// nrs.harvard.edu/urn-3:HUL.InstRepos:dash.current.terms-of-use\#LAA

\section{Share Your Story}

The Harvard community has made this article openly available.

Please share how this access benefits you. Submit a story.

Accessibility 


\section{Networked Policy Series}

Translating Research for Action:

Ideas and Examples for

Informing Digital Poliey

Networked Research Briefing

Policymaking Avenues

Assessing the Role of Academics in Digital Policy

Amar Ashar, Rob Faris, and Urs Gasser
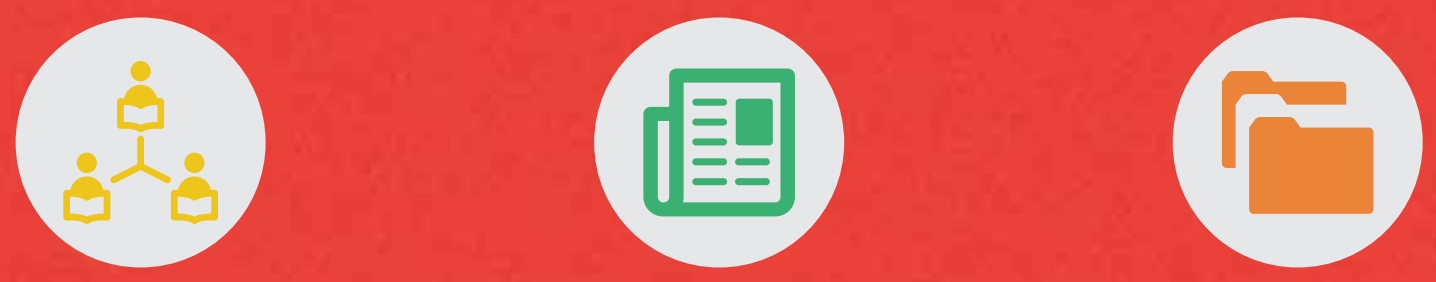

for more from this series visit

cyber.harvard.edu

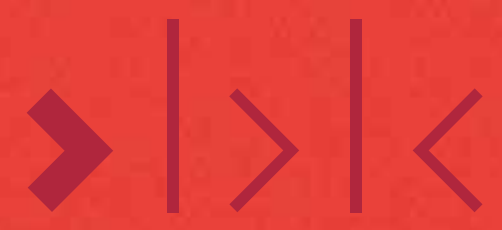




\title{
$>|>|<$ \\ BERKMAN KLEIN CENTER \\ FOR INTERNET \& SOCIETY AT HARVARD UNIVERSITY
}

\section{Networked Policymaking Avenues}

Assessing the Role of Academics in Digital Policy

\author{
Amar Ashar, Rob Faris, and Urs Gasser
}

Suggested citation: Ashar, Amar, Faris, Robert and Gasser, Urs, Networked Policy Making Avenues: Assessing the Role of Academics in Digital Policy (September 23, 2016). Networked Policy Series, Berkman Klein Center Research Publication No. 2016-14. Available at SSRN: http://ssrn.com/ abstract $=2842796$

23 Everett Street | Second floor | Cambridge, Massachusetts 02138 +1 617.495.7547 | +1 617.495.7641 (fax) | http://cyber.harvard.edu press@cyber.harvard.edu 


\section{Acknowledgments}

The authors gratefully acknowledge the support and help of the many people who shared comments and ideas with us, including workshop attendees at the Internet Governance Forum 2015 and participants at a meeting focused on digital issues in Latin America that took place in April 2016 in Buenos Aires, as well as the Ford Foundation for their support. This paper and the other briefings included as part of the Networked Policy Series are generously supported by the Ford Foundation and the John D. and Catherine T. MacArthur Foundation.

\section{About the Berkman Klein Center for Internet \& Society}

The Berkman Klein Center for Internet \& Society at Harvard University is dedicated to exploring, understanding, and shaping the development of the digitally-networked environment. A diverse, interdisciplinary community of scholars, practitioners, technologists, policy experts, and advo-cates, we seek to tackle the most important challenges of the digital age while keeping a focus on tangible real-world impact in the public interest.

\section{Introduction}

The prevalence of highly dynamic networked technologies in our daily lives presents novel challenges to policymakers. Digital technologies transcend geographic boundaries, accelerate information flows, and test the ability of economic, political, and social institutions to handle threats and seize opportunities. Well-informed digital policy has the ability to enable societies and markets to flourish. Poorly informed policy has the potential to inhibit innovation and place burdensome limitations on civic participation and human rights. Experience and knowledge of the digital arena by policy-makers is advancing rapidly but still lags behind the scale and pace of change.

Traditional methods and practices for addressing policy issues do not adequately serve decision makers facing highly technical, complex, and globally relevant questions. Academics have a unique and important role to play in promoting evidence-based policymaking by facilitating the application of academic knowledge to policymaking processes. When speaking with an informed and independent voice in the public interest, scholars and educators are frequently afforded a position of credibility and authority on complex policy questions and matters of public import.

While the uses of digital technologies introduce new policy problems, the emergence of the networked public sphere also has the potential to transform policymaking processes and to help foster better policy that supports innovation and protects human rights. Several distinctly different channels are available to inform and impact policymaking and to strengthen awareness of digital policy issues among all stakeholders. For academics, this opens many opportunities to play productive roles in crafting robust digital policies. 


\section{Networked Policymaking}

There are a growing number of examples that point toward a change in the way public policy is made in the digital age. This new context, which we refer to as networked policymaking, involves a greater variety of actors and voices, often collaborating in formal and informal networks, taking part in a public consideration and debate of policy questions via digital media. Academics, activists, advocates, industry representatives, nonprofits, and the public at large are all active participants in this arena. Their interactions form a complex system that shapes and informs policymaking. This may involve bringing issues to the forefront of public attention, producing alternative frames for policy dialogues, providing a platform for new information, research, and expert opinion, swaying public opinion, or organizing collective action.

In the past several years, we have seen several cases that highlight the great potential for networked academic actors to inform policymaking. Major legislative efforts, such as the SOPA/PIPA debate in the United States, have included active participation from digital policy experts. Regulatory battles, such as the Net Neutrality debate in India, demonstrate how locally and globally networked actors directly impact outcomes. Political frameworks, such as the EU Safe Harbor Agreement, illustrate how policy choices may benefit from input and analysis from legal experts across jurisdictions. Judicial decisions, such as those which have led to a number of shutdowns of WhatsApp in Brazil in 2015 and 2016, show the immediate impact policy decisions can have on everyday users of digital services and how scholars (and other stakeholders) can advocate for accountability mechanisms. And law enforcement actions, such as the Apple/FBI encryption controversy, exhibit the need for critical analysis and debate. Academic evidence, insight, and participation, often manifest through digital networks, have been critical to all of these policy efforts.

What has changed? Digital technologies have transformed both the process and substance of major policy debates across the globe. Traditional policymaking activities have heavily relied on inputs and procedures from small groups of people, companies, and organizations. The Internet has allowed policymakers, as well as other stakeholders, to experiment with mechanisms for much broader consultations, crowdsourced idea generation, and interactive participation platforms.

Many current policy choices involve tradeoffs that are infused with novel value judgments. For instance, policies that promote data accessibility and flow may challenge notions of user privacy; instances of harmful and hateful speech online may contradict conceptions of freedom of speech; debates over Net Neutrality present questions over the balance between free markets and regulation; and controversies over state security mechanisms and user or device security highlight ongoing debates over trust. The societal norms around these tradeoffs are not yet fully formed. Networked policymaking approaches can assist in the evaluation of tradeoffs in such value systems. Compared to purely technical policy questions, this suggests that greater participation in policymaking is a good idea.

For academics, playing a productive role in policymaking through these interfaces requires not only a strong foundational knowledge of a topic but also the skills, resources, and connections to engage with the diverse set of constituencies involved in public policy debates. Scholars must build knowledge and capacity among peers and across fields, as well as across sectors and among diverse stakeholders, in order to have an impact. 


\section{A Draft Framework}

In this document, we seek to (1) describe the different avenues and modalities in which academics can have an impact on policy, and (2) offer a framework to help researchers and other constituents assess the role of academics in policymaking. We hope that this may serve to help researchers build research agendas and policy roadmaps for engagement in specific locales and around salient policy issues. Although the focus of this document is on academics and policymaking, the questions of priorities, focus, and emphasis should be informed by the perspectives and insights of all the various stakeholders that interact, support, and draw upon academic work.

This document emerged from and was informed by meetings about networked policymaking convened by the Global Network of Internet \& Society Centers ${ }^{1}$, including one which took place at the Internet Governance Forum in João Pessoa, Brazil in November 2015, as well as a workshop focused on Internet policy issues in Latin America that took place in Buenos Aires in April 2016. It is intended to help frame and propel forward the conversation. The discussion included a diverse set of stakeholders from academic, civil society, government, and industry from a wide array of coun-tries and regions. We attempt to elaborate on the key questions discussed and offer a set of criteria that actors in the networked policymaking space may consider as they construct research agendas.

\section{Exploring Avenues of Impact}

For academics with an interest in public policymaking, there are many paths to impact. In addition to traditional mechanisms within academic communities to build policy-relevant evidence and knowledge, there are options for direct engagement with policymakers, as well as a range of indirect approaches- such as engagement with the public, nonprofits, companies, and the media-that offer potential pathways for scholars to apply academic insight. The shift in context to a networked media and policy debate environment has enabled scholars to deepen the impact of their research by working through networks.

There are several interfaces between academics and other stakeholders that present opportunities to address policy challenges. These interfaces also highlight areas where expanding efforts and emphasis may be fruitful and where academics may identify gaps in knowledge or capacity. This framework may serve as a navigation aid to researchers who want to decide which topics to focus on in coming years and what mode of activity can be employed to have maximum impact.

1 http://networkofcenters.net/ 


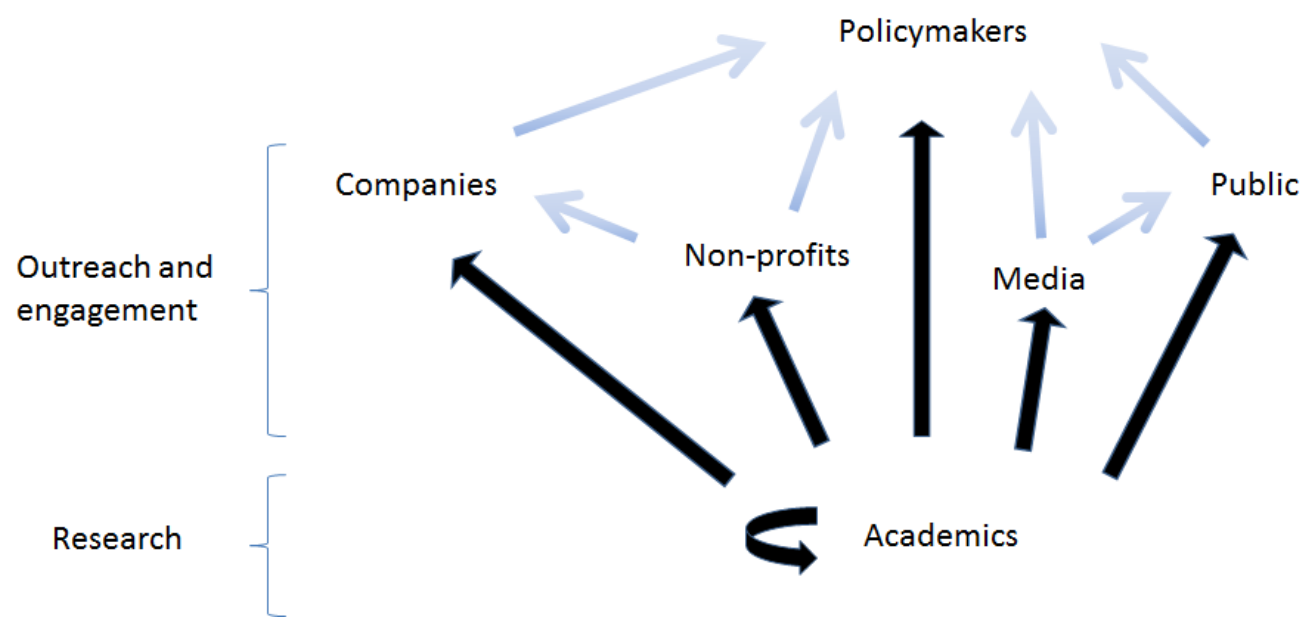

For each avenue, there are likely to be unique opportunities for researchers to strengthen their impact, whether working in conjunction with civil society, media, industry, or government representatives. The nature and value of each interface are described here:

\begin{tabular}{|l|l|}
\hline Academics $\leftrightarrow$ Academics & $\begin{array}{l}\text { The need for research is driven by uncertainty or lack of } \\
\text { information within a certain field or a specific research question. } \\
\text { Academic scholarship provides a base of evidence all other } \\
\text { actors draw from in order to make arguments about their } \\
\text { positions and to demonstrate the need for change. }\end{array}$ \\
\hline Academics $\leftrightarrow$ Policymakers & $\begin{array}{l}\text { Many policymakers lack basic a basic understanding of key } \\
\text { Internet and digital technology issues and some seek academic } \\
\text { input when faced with complex digital policy questions. }\end{array}$ \\
\hline Academics $\leftrightarrow$ Media & $\begin{array}{l}\text { Journalists help to shape public understanding and policymaker } \\
\text { knowledge of digital policy but depend on academic work for } \\
\text { context, reference, and commentary. }\end{array}$ \\
\hline Academics $\leftrightarrow$ Nonprofits & $\begin{array}{l}\text { Nonprofits seek to build credibility and support for issues by } \\
\text { assembling multistakeholder coalitions, by raising issues of } \\
\text { public concern, and drawing from evidence and scholarly insight } \\
\text { to support their positions. }\end{array}$ \\
\hline Academics $\leftrightarrow$ Companies & $\begin{array}{l}\text { The exchange of data, information, and perspectives between } \\
\text { companies and academics related to digital policy can help } \\
\text { to shape company practices and policies, as well as inform } \\
\text { academic work and help all parties to more fully understand the } \\
\text { implications of different policy choices. }\end{array}$ \\
\hline Academics $\leftrightarrow$ Public & $\begin{array}{l}\text { Public understanding of Internet policy issues is often strongly } \\
\text { informed by academic policy experts, particularly when they } \\
\text { are able to synthesize and translate technical knowledge. } \\
\text { Public awareness of and engagement with digital policy has at } \\
\text { times dramatically reshaped how decision makers manage } \\
\text { their priorities. }\end{array}$ \\
\hline
\end{tabular}




\section{Interfaces \& Modalities}

For each of the avenues and interfaces described above, the modalities of outreach and engagement will vary. For example, some rely more heavily on primary research, while others may rely on synthesis and communication of findings, or network building. The different modalities may involve the flow of ideas and people between groups as well as distinct tools and activities that can be employed to increase impact based on the strengths and positions of the stakeholders involved. In selecting an area of focus, scholars must make the choice whether to invest time and resources in conducting further research, in synthesizing and translating existing knowledge for non-academic audiences, or in any number of other activities that contribute to policy formation. Each avenue draws on different sets of capabilities and requires different resources while presenting questions about values, tactics, and strategy.

\section{Within academic communities:}

- Depending on the maturity of a debate and our current state of knowledge, scholars may seek to advance the body of knowledge of a topic area, apply research methods to areas where evidence is lacking or knowledge gaps exist, and address awareness issues by more broadly disseminating and communicating insights to peers in order to build collective understanding. Modalities at this interface include:

" Academic publishing and peer review through traditional outlets;

» Collaboration and network building;

» Conferences and other convenings;

»Education and the production of educational materials and tools.

\section{Academic-policymaker interface:}

- Academics working with policymakers can act to fill knowledge gaps and impact policy outcomes and engage directly with policymakers to advocate for and advance the public interest. Modalities at this interface include:

- Meetings and direct dialogue with policymakers;

» Formal submission of policy proposals and commenting on policy initiatives;

» Targeted primary research, data gathering, and analysis;

» Creation of policy briefs intended for public sector audiences.

\section{Academic-media interface:}

- A strong interface between academics and the media can contribute to public awareness and literacy of digital policy matters, illuminate topics that are not receiving the attention they deserve, amplify underrepresented voices and opinions, and prompt academics to synthesize complex debates. Media also act as a check and balance mechanism to government. Academic collaboration with media can serve to increase transparency and accountability by supporting journalism with robust evidence. Modalities at this interface include:

» Interviews and informational briefings;

» Meetings and workshops;

» Media guides and briefings. 


\section{Academic-nonprofit sector interface:}

- Advocates and activists partnering with academics can strengthen their prospects to affect change by drawing from scholarship to support arguments and positions, mobilizing communities of interest around specific policy issues, and translating complex policy debates into briefings and broadly accessible articles arguing for specific policy change in front of legislators and influencers. Modalities at this interface include:

» Briefings and production of materials designed for funding and advocacy organizations;

» Targeted research;

» Meetings and workshops;

» Strategic alliances and collaboration;

» Participation in multistakeholder bodies.

\section{Academic-private sector interface:}

- Strengthening the interface between academics and companies will enable industry to continue to benefit from academic expertise, inform company behavior, allow scholars to benefit from the data and services produced by digital commercial innovation, and promote the development of standards and measures that can be incorporated into digital policies that support innovation. Modalities at this interface include:

» Briefings and meetings;

» Informational exchange and data sharing;

» Participation in multistakeholder bodies.

\section{Academic-public interface:}

- Academic scholarship serves to create broader public awareness of pressing Internet policy issues that may impact users and citizens on a daily basis. Researchers can foster public awareness and sentiment-an important driver for policymaker agendas-support participation and consultation in policymaking processes through education and outreach to the public, and highlight and elevate public voices in debates related to digital policy. Modalities at this interface include:

» Publication of research findings designed for broader public audiences and in easily accessible venues;

» Active social media presence;

»Creation of public-facing portals, platforms, and tools. 
As the potential impact of researchers on matters of public policy increases, scrutiny of their work rightly increases as well. This scrutiny may take many forms, from challenges to methodology and accuracy based entirely on scientific merit to less well-grounded attacks that are instigated by those with a political agenda or a stake in the outcome. While outside of the scope of this short paper, the mech-anisms of peer review and validation of research are also evolving, enabling new opportunities for academics and others who draw conclusions based on research to substantiate findings and respond to critique, including claims of bias. Within the networked policymaking space, there has been growing attention to the role of funding sources and the potential for conflict of interest. We believe that this scrutiny is ultimately healthy and will help to promote better more objective research. It does place an added burden on researchers who must be careful in matching research and funding sources, and withstand challenges to their integrity, even when unfounded. Actors participating within each of the interfaces described here should consider such potential conflicts of interest when evaluating opportunities and approaches.

Many of the opportunities for academic work to shape digital policy are mediated through the efforts and relationships of nonprofit organizations, the media, the private sector and the public. As such, academic participation and collaboration within this networked system acts as support-ive infrastructure to other interfaces and avenues scholars may not be directly involved in.

\section{Contextual Factors}

Across all avenues, there are contextual factors, which either enable or inhibit activities designed to positively shape policy. We summarize a selected number of the factors that may improve opportunities or present obstacles across the various interfaces here.

\begin{tabular}{|c|c|c|}
\hline & Enablers & Obstacles \\
\hline Awareness & $\begin{array}{ll}\text { - } & \text { Broad awareness of the } \\
\text { importance of digital } \\
\text { technologies in daily life } \\
\text { - } & \text { Familiarity with digital } \\
\text { policy issues }\end{array}$ & 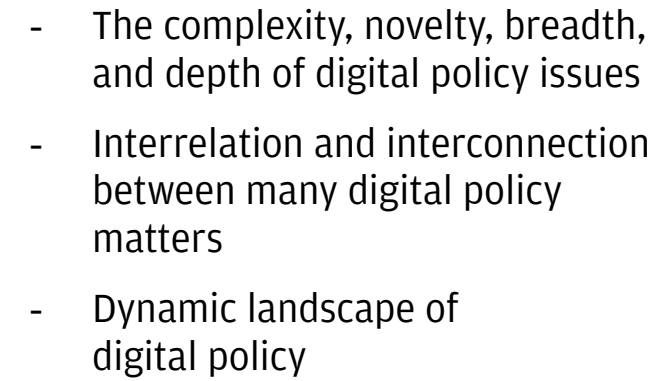 \\
\hline $\begin{array}{l}\text { Existing networks } \\
\text { and relationships }\end{array}$ & $\begin{array}{ll}\text { - } & \text { Robust venues and } \\
\text { channels of communication }\end{array}$ & $\begin{array}{ll}\text { - } & \text { Poor information flows } \\
\text { - } & \text { Weak interfaces } \\
& \text { between sectors }\end{array}$ \\
\hline
\end{tabular}




\begin{tabular}{|c|c|c|}
\hline $\begin{array}{l}\text { Existing law } \\
\text { and policy }\end{array}$ & $\begin{array}{l}\text { Established structures } \\
\text { and mandates to address } \\
\text { common problems }\end{array}$ & $\begin{array}{l}\text { Pace of policymaking may not } \\
\text { keep pace with technological } \\
\text { development } \\
\text { - The speed, scale, and global } \\
\text { nature of technology exacerbates } \\
\text { regulatory problems }\end{array}$ \\
\hline $\begin{array}{l}\text { Institutional } \\
\text { incentives and } \\
\text { environment }\end{array}$ & $\begin{array}{l}\text { Financial, human, and } \\
\text { institutional resources to } \\
\text { support scholarship, tech } \\
\text { development, advocacy and } \\
\text { policy advancement }\end{array}$ & $\begin{array}{ll}\text { - } & \text { Inadequate funding } \\
\text { - } & \text { Poor distribution of resources } \\
& \text { across people, organizations, } \\
& \text { structures, and geographies } \\
\text { - } & \text { Incompatible incentive structures }\end{array}$ \\
\hline $\begin{array}{l}\text { Interest and } \\
\text { receptivity of other } \\
\text { stakeholders to } \\
\text { academic input }\end{array}$ & $\begin{array}{ll}\text { - } & \text { Interest in and active } \\
\text { engagement with academic } \\
\text { work } \\
\text { - } \quad \text { Interests aligned and } \\
\text { coordinated strategies for } \\
\text { intervention }\end{array}$ & $\begin{array}{ll}\text { - } & \text { Divergent priorities } \\
\text { - } & \text { Failure to translate knowledge to } \\
\text { non-academic audiences } \\
\text { - } & \text { Paucity of policy relevant work }\end{array}$ \\
\hline $\begin{array}{l}\text { Current political and } \\
\text { economic climate }\end{array}$ & $\begin{array}{l}\text { Shared values and } \\
\text { understanding of } \\
\text { opportunities to strengthen } \\
\text { digital policymaking }\end{array}$ & 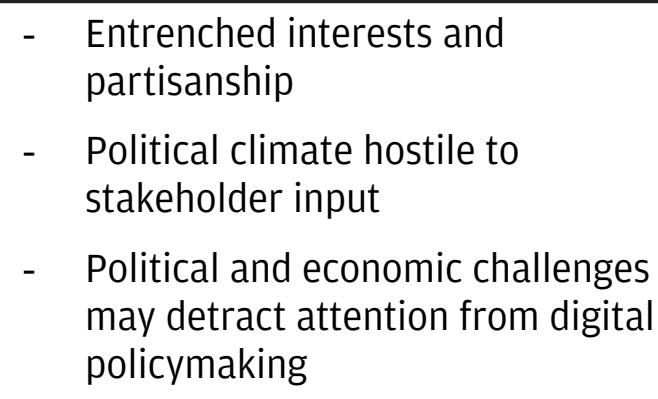 \\
\hline $\begin{array}{l}\text { Events and external } \\
\text { factors }\end{array}$ & 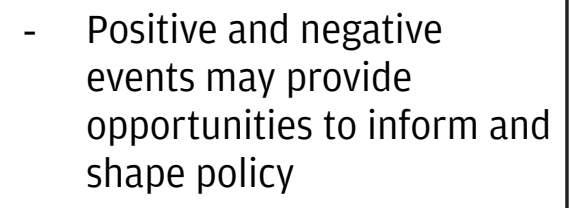 & $\begin{array}{l}\text { Major events may shift priorities } \\
\text { away from digital policy or } \\
\text { provide a basis for pushing } \\
\text { forward poor policies }\end{array}$ \\
\hline $\begin{array}{l}\text { Structural and } \\
\text { societal challenges } \\
\text { such as inequality, } \\
\text { poverty, and } \\
\text { marginalization }\end{array}$ & $\begin{array}{l}\text { - Structural problems } \\
\text { provide an avenue for } \\
\text { collaboration on digital } \\
\text { policy }\end{array}$ & $\begin{array}{l}\text { - Structural issues impede effective } \\
\text { broad-scale participation and } \\
\text { representation }\end{array}$ \\
\hline
\end{tabular}




\section{Strengthening A Networked Approach to Digital Policymaking}

Effective impact cannot be attained by investing in only one of the avenues or actions described. Rather, impact depends on strong direct, indirect, and mediated interfaces and must be pursued through of a suite of such activities, including:

- Communication, Translation, and Amplification: Researchers can work with each stakeholder to experiment with different strategies designed to clearly communicate scholarly findings. Academics must also act as translators by publicly presenting their work, sharing their research in multiple formats and modalities, and engaging in networks that help research spread across national boundaries. Academics can further develop their relationships with media to widely disseminate and amplify learnings-scholars are often called upon to provide background and context on pressing digital policy issues of the day and academic voice in public conversation adds an important dimension of analysis and perspective. When utilized collectively by scholars, these activities can greatly aid policymakers and other audiences who are not able to easily access academic analysis.

- Access: Scholars can enrich the interface between academia and the public by sharing findings in public-facing publishing platforms and popular fora, as well as distributing outputs in different media formats. Additionally, academics can make research more accessible through open access practices and by participating in public conversations and events.

- Collaboration: Scholars interact with every actor in the networked policymak-ing space and should consider how to strengthen each relationship as well as the entirety of the ecosystem. The modalities described offer a starting point for collaborators to explore what tools and mechanisms are most effective when working to impact digital policy. Individual scholars and institutions are increasingly playing more active advocacy roles within the digital policymaking space-some scholars even take leave to act in official policy roles-and both continue to navigate new approaches as they contribute to policy conversations.

- Evaluation: Degree of impact also depends on what activities stakeholders choose to pursue. Whether scholars invest their time into translating their research into broadly accessible forms, interacting with the media to provide context and expertise, or talking directly to policymakers, each choice requires an evaluation of what tactics and strategies will be most effective. An assessment of tradeoffs and costs should be conducted against the landscape of individual and collective benefits and opportunities. 
- Further Research: Researchers should embrace the dynamic landscape of digital policymaking and employ it as a subject and mode to advance understanding of policy matters. The definition of "research" we use here is broad and inclusive; scholarly efforts in the networked public sphere are inclusive of the actions and active participation of other stakeholders looking to inform policymaking.

\section{Opportunities and Strategic Choices}

As described here, there are a wide array of avenues by which academics can shape policy. There are opportunities to inform policy at each of the interfaces we describe, and these oppor-tunities depend on a set of contextual factors. They may arise around the timing of a specific policy decision or may reflect unmet potential at one of the network interfaces that has been shown to be particularly useful in another country or another policy debate.

Sonia Livingstone frames the choice for academics who seek to interact with policymaking in terms of "push and pull." She describes how:

There is more than one model of evidence-based policy making in circulation. The 'push' model typically favoured by academics -according to which knowledge is disseminated to policymakers in the form and at the time that suits academics - is of limited value, since academic writing is not only little understood but is easily misunderstood, and it easily misses its mark. The 'pull' model, by contrast, is often experienced as unduly onerous by academics: in this problem-solving model, policymakers seek out research findings to address a specific question or problem, but of course academics are rarely at leisure to answer the question with the urgency expected of them, and so both sides are often frustrated. Both push and pull models, although the most obvious, suffer the limitations consequent upon the typically poor relations sustained between academics and policymakers; if neither knows how the other works, of the nature of their concerns and the demands upon them, then their interactions are likely to prove frustrating.?

The push and pull model helpfully illustrates the differences between scholars and policymakers acting in traditional roles and modalities, and indicates steps to address this problem. For actors in the networked policymaking sphere, each must consider their strengths, tools at hand, and position within the ecosystem in order to determine the fastest and most effective path to impact policy. Academics may contemplate proactive and responsive approaches as they attempt to set a policy agenda, complementary to the push and pull mechanisms described by Livingstone. Proactive approaches impact policy through foundational research and outreach and engagement. Responsive approaches respond to and incorporate opportunities and topical focus as they arise. Both have benefits and challenges associated with them and are dependent on many of the factors described. Deciding where to focus academic resources and energy is going to depend on the contextual factors and an assessment of the opportunities at each one of the interfaces (and its modalities) for research topics academics that want to pursue further. Opportunities are thus topic, interface, and modality specific. Academics operating in networked policy environments may use the framework described here to evaluate the opportunity landscape and determine shared priorities and pathways to policy advancement.

$2 \quad$ Livingstone, Sonia (2013) 'Knowledge enhancement': the risks and opportunities of evidence-based policy. In: O'Neill, Brian, Staksrud, Elisabeth and Mclaughlin, Sharon, (eds.) Towards a Better Internet for Chil-dren: Policy Pillars, Players and Paradoxes. Nordicom, Goteborg, Sweden. 


\section{Conclusions}

» Opportunities for academics to further engage in policymaking are plentiful Direct and indirect avenues to impact policymaking offer many options for researchers to consider. This framework attempts to better position the academic space to be ready to take advantage of such opportunities when they appear.

» Networked problems require networked solutions

Scholars must collaborate with other stakeholders in order to increase understanding of issues and use networked approaches to better inform digital policymaking. Globally and locally coordinated networks of diverse actors are better situated to respond to the dynamics of the digital policymaking space.

» Nurturing and sustaining networks requires a concerted effort

Actively and effectively engaging in digital policymaking requires a dedicated effort to build capacity and expertise and an investment in forming and maintaining networks. Researchers, advocates, activists, policymakers, and industry players must establish networks as foundations to act and build upon in order to advance the public interest in meaningful and impactful ways. 